\title{
Examples of successful numerical modelling of complex geotechnical problems
}

\author{
H. F. Schweiger ${ }^{1}$. C. Fabris ${ }^{1} \cdot$ G. Ausweger ${ }^{1} \cdot$ L. Hauser ${ }^{1}$
}

Published online: 4 December 2018

(c) The Author(s) 2018

\begin{abstract}
Over the last decades, numerical methods have gained increasing importance in practical geotechnical engineering and numerical methods have become a standard tool in geotechnical design, widely accepted by the geotechnical profession. The advantages of numerical analyses for solving practical problems have been recognised, and developments in software and hardware allow their application in practice with reasonable effort. However, there is still a gap between practice and research and, often unnecessary, simplifications are made in practice and therefore the full power of numerical analyses is not always utilised. One reason for this discrepancy is a lack of transfer of knowledge from research into practice but also a lack of theoretical background of numerical methods, constitutive modelling and modern soil mechanics in practice. In this paper, the application of advanced numerical models for solving practical geotechnical problems is shown, whereas the examples have been chosen in such a way that different aspects are highlighted in each case. Results from fibre-optic measurements for a pull-out test of a ground anchor in soft soil could be reproduced by employing advanced constitutive models, in particular for the grout, in the bonded length of the anchor. For this test, a class-A prediction has been made and numerical results have then been compared with in situ measurements. The back-analysis of a slow-moving landslide is presented next, where the rate of deformation is influenced by water level changes in a reservoir for a pumping power plant, creep of lacustrine sediments and environmental effects such as rainfall infiltration. Finally, some results of modelling cone penetration testing in silts are presented highlighting the effects of anisotropic permeability.
\end{abstract}

Keywords Finite element analysis $\cdot$ Anchor load test $\cdot$ Slope stability $\cdot$ CPT

\section{Introduction}

Numerical methods have proven to be an important and powerful tool for solving practical geotechnical problems. This has been possible on the one hand because finite element/finite difference codes have been developed to a stage that they can be easily operated by geotechnical engineers. On the other hand, constitutive models which are able to describe important features of soil behaviour have been implemented in a robust manner in these codes, although it has to be emphasised that open questions in soil modelling remain and there is still no generally accepted constitutive model for soils available.

H. F. Schweiger

helmut.schweiger@tugraz.at

1 Institute of Soil Mechanics, Foundation Engineering and Computational Geotechnics, Graz University of Technology, Graz, Austria
Although the advantages of numerical modelling are obvious, it has to be mentioned that the role of numerical analyses in geotechnical engineering is different as compared to other engineering disciplines such as, for example, mechanical or structural engineering. The reasons for this are specific aspects of geotechnical engineering, such as

1. In geotechnics, the "construction material" is natural ground (soil and rock) and not man-made such as concrete and steel, fabricated to predefined specifications. This inevitably means that the material is inhomogeneous, its mechanical and hydraulical behaviour is not easily formulated in mathematical terms and material parameters are difficult to determine.

2. Even with a perfect site investigation scheme, significant uncertainties remain with respect to the soil profile and thus with the geotechnical model which forms the basis for the numerical model. 
3. Installation processes, such as construction of piles, diaphragm walls, stone columns, mixed-in-place columns, jet grout panels, have an influence on the stress regime in the soil, which is still extremely difficult, if not impossible, to quantify numerically.

4. Geometric simplification has to be introduced (2D vs $3 \mathrm{D}$ ), and the domain of the model to be analysed may not always be easily identified.

In the following, an attempt is made to show the benefits of using numerical methods in geotechnical engineering by means of practical examples, addressing an in situ anchor load test, a complex slope stability problem and cone penetration testing.

\section{Example: anchor pull-out test}

\section{Soil conditions and test arrangement}

Analysing an anchor pull-out test by means of numerical modelling provides a very useful tool not only to predict the ultimate load of the anchor but also to have a better insight into the interactions between the tendon, the grout and the soil. In this particular case, a class-A prediction of an in situ test was performed and these results were subsequently compared with the in situ performance of the tested anchor. The monitoring system not only involved the standard set-up for an anchor load test to obtain the load-displacement curve but included fibre-optic measurements in tendon and grout of the anchor. In this way, for example, cracking of the grout in the bonded length could be identified. In order to take into account cracking in the numerical model, an advanced constitutive model for the grout has been employed. The test was performed on a construction site in St. Kanzian, Austria. The anchor was vertically installed, was post-grouted and had a free length of $12 \mathrm{~m}$ and a fixed length of $8 \mathrm{~m}$, respectively.

Laboratory testing of soil samples extracted close to the test area classified the soil as clayey, sandy silt of low plasticity and the grain size distribution was approximately $70 \%$ silt, $15 \%$ clay and $15 \%$ sand. Direct shear tests and oedometer tests were performed in samples located at $17 \mathrm{~m}$ depth and $24 \mathrm{~m}$ depth. In addition, a seismic dilatometer test (sDMT) was conducted to determine the shear wave velocity. The soil is referred herein as "seeton". Thin sand layers are also present. Based on this information, the parameters for the employed constitutive model (the Hardening Soil Small model as implemented in the finite element code Plaxis 2D) were determined (see Table 1). The tendon was modelled as a linear elastic material and the grout with the so-called Plaxis Shotcrete model, which is a nonlinear constitutive model allowing for post-peak softening in compression and tension and is therefore able to capture the development of cracking in the grout, at least in an approximate manner. Parameters are summarised in Table 2. For more details on this model, the reader is referred to Schädlich and Schweiger [9].

Table 1 Parameters for "seeton"

\begin{tabular}{lllll}
\hline Parameter & Description & Unit & Seeton & Sand \\
\hline$E_{50, \text { ref }}$ & Primary loading stiffness at ref. pressure & $\mathrm{kPa}$ & 6625 & 24,000 \\
$E_{\text {oed,ref }}$ & Oedometric stiffness at ref. pressure & $\mathrm{kPa}$ & 5300 & 24,000 \\
$E_{\text {ur,ref }}$ & Un/reloading stiffness at ref. pressure & $\mathrm{kPa}$ & 48,000 & 72,000 \\
$G_{0 \text { ref }}$ & Small strain shear modulus & $\mathrm{kPa}$ & 120,000 & 120,000 \\
$\gamma_{0.7}$ & Shear strain at $70 \% G_{0 \text { ref }}$ & - & $0.15 \mathrm{E}-3$ & $0.15 \mathrm{E}-3$ \\
$c^{\prime}$ & Effective cohesion & $\mathrm{kPa}$ & 10 & 5 \\
$\varphi^{\prime}$ & Effective friction angle & $\circ$ & 29 & 35 \\
\hline
\end{tabular}

Table 2 Tendon and grout properties

\begin{tabular}{lllll}
\hline Parameter & Description & Unit & Tendon & Grout \\
\hline$E$ & Young's modulus & $\mathrm{kPa}$ & $195,000,000$ & $16,260,000$ \\
$f_{\mathrm{c}, 28}$ & Uniaxial compressive strength & $\mathrm{kPa}$ & - & 32,120 \\
$f_{\mathrm{t}, 28}$ & Uniaxial tensile strength & $\mathrm{kPa}$ & - & 2000 \\
$G_{\mathrm{c}, 28}$ & Compressive fracture energy & $\mathrm{kN} / \mathrm{m}$ & - & 50 \\
$G_{\mathrm{t}, 28}$ & Tensile fracture energy & $\mathrm{kN} / \mathrm{m}$ & - & 0.15 \\
$f_{\mathrm{tun}}$ & Ratio residual/peak tensile strength & - & - & 0.05 \\
$\varphi^{\prime}$ & Maximum friction angle & $\circ$ & - & 40 \\
\hline
\end{tabular}




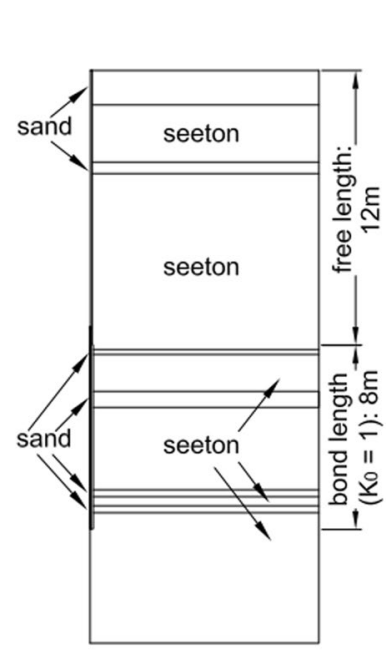

(a)

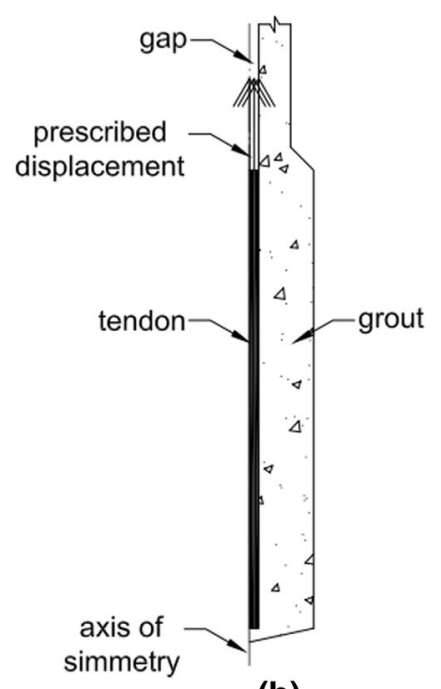

(b)
Fig. 1 Model geometry a overview and $\mathbf{b}$ anchor detail

\section{Numerical model and simulation results}

The numerical simulation was performed using the finite element software Plaxis 2D 2016 [4]. Because the anchor was installed vertically, the model is axisymmetric and only half of the anchor geometry was modelled. The model geometry is presented in Fig. 1. The tendon was considered only in the fixed length, and the grout was applied in the free and fixed length, whereas pressure grouting was only assumed in the latter. The load was applied by means of vertical prescribed displacements on top of the tendon. The pressure grouting was considered by increasing the radial stresses along the entire section comprising the fixed length and thus the earth pressure coefficient at rest $\left(K_{0}\right)$ was set equal to one. In addition, the diameter of the bonded section was increased to $280 \mathrm{~mm}$ (borehole diameter was $178 \mathrm{~mm}$ ) based on the amount of grout pumped into the soil. It is acknowledged that this approach of taking into account the effects of pressure grouting is highly simplified; nevertheless, it can be justified from a practical point of view and can be considered to be sufficient for the purpose of this study.

Figure 2a shows the load-displacement curves obtained numerically (class-A prediction) and measured results. The behaviour in the numerical model is slightly stiffer, but it has to be taken into account that in the test the load has been kept constant at each loading stage and the "creep" has been measured. Up to about $1100 \mathrm{kN}$, the "creep" was small; however, in the numerical model, it is completely neglected. At $1100 \mathrm{kN}$, the creep increased significantly, and according to testing standards, this would be considered as failure. Considering these aspects, the comparison between prediction and test results can be considered very reasonable. The shear stress distribution along the interface grout-soil is presented in Fig. 2b and, as expected, stresses are higher within the stiffer sand layers. The ultimate pull-out load of about $1100 \mathrm{kN}$ is achieved when the maximum shear stress is mobilised along the entire fixed length.

The contribution of the grout on the strain distribution along the tendon can be evaluated by the tension softening parameter $H_{\mathrm{t}}$, an output of the Shotcrete model. If $H_{\mathrm{t}}$ exceeds zero, softening in tension starts and cracks start to develop, leading to an increase in the strains along the tendon. If $H_{\mathrm{t}}$ is larger than 1 , the tensile stress decreases to its residual value (practically zero) and the strains oscillate along the tendon. The strain distribution in the tendon and the variation of $H_{\mathrm{t}}$ in the grout are shown in Fig. 3a, b. Although an exact comparison with respect to crack location is not possible, a qualitative assessment can be made as shown in Fig. $4 \mathrm{a}, \mathrm{b}$ where strains from the fibre-optic measurements in the grout and the $H_{\mathrm{t}}$-parameter are compared for different
Fig. 2 Numerical results a load-displacement curve and $\mathbf{b}$ shear stress distribution

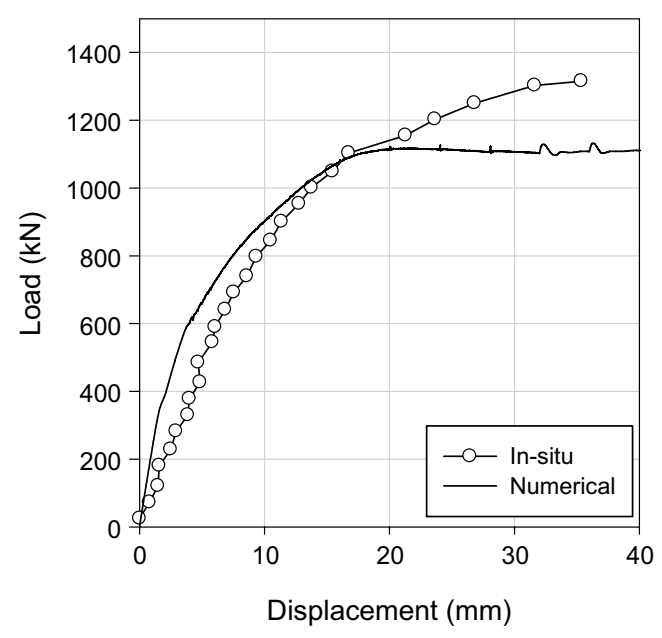

(a)

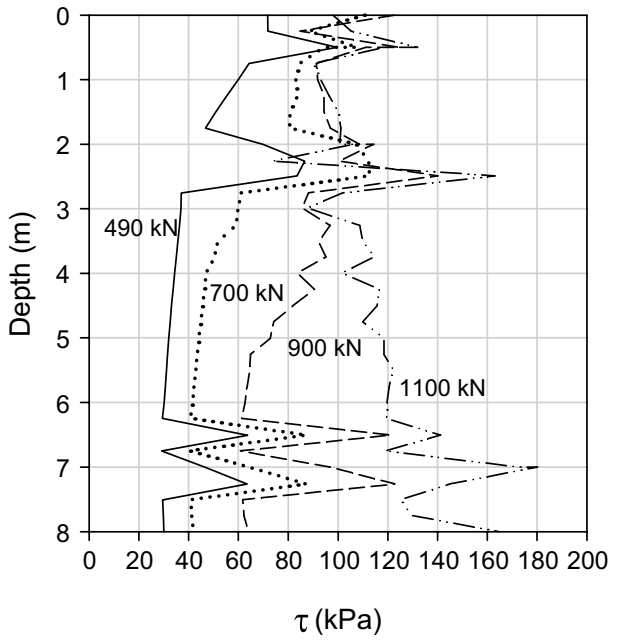

(b) 
Fig. 3 Numerical results a strains along the tendon and $\mathbf{b}$ $H_{\mathrm{t}}$ distribution in the grout
Fig. 4 Crack development in grout of fixed length-numerical results versus measurements

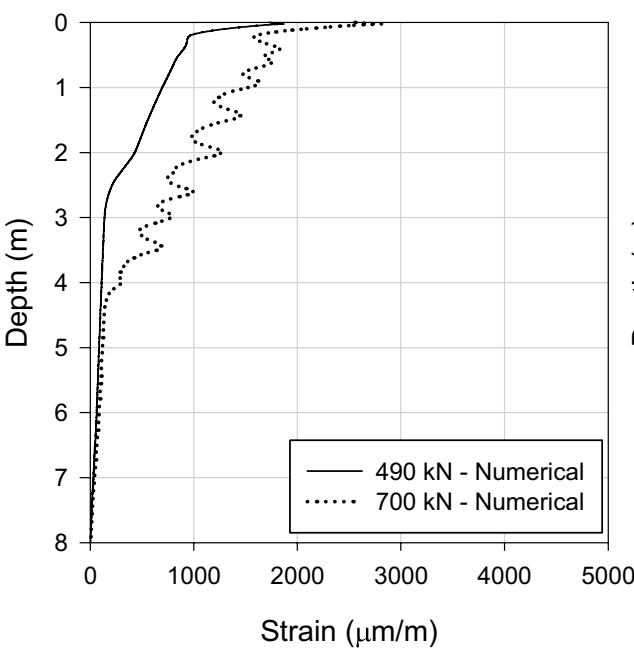

(a)

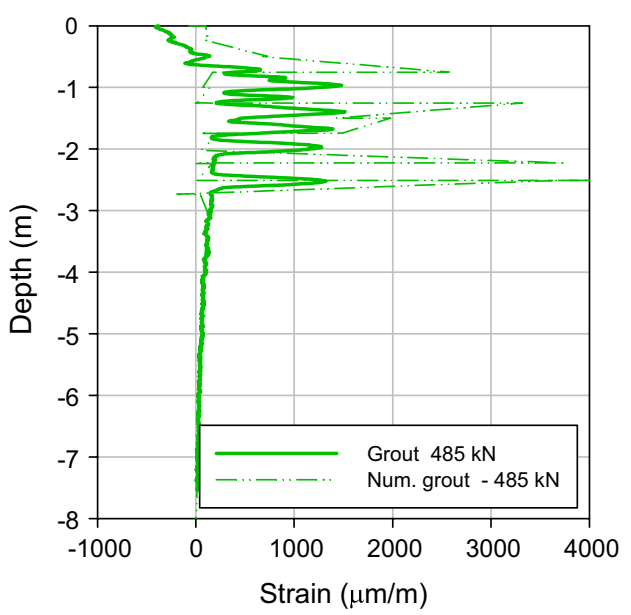

(a)

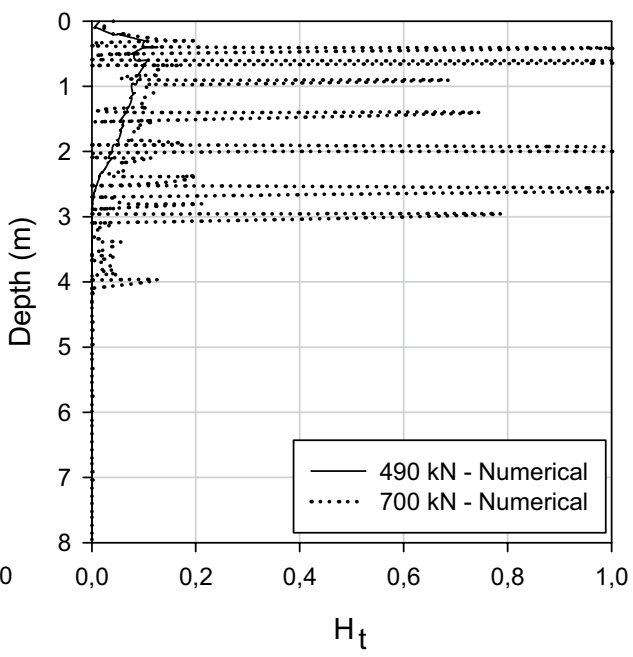

(b)

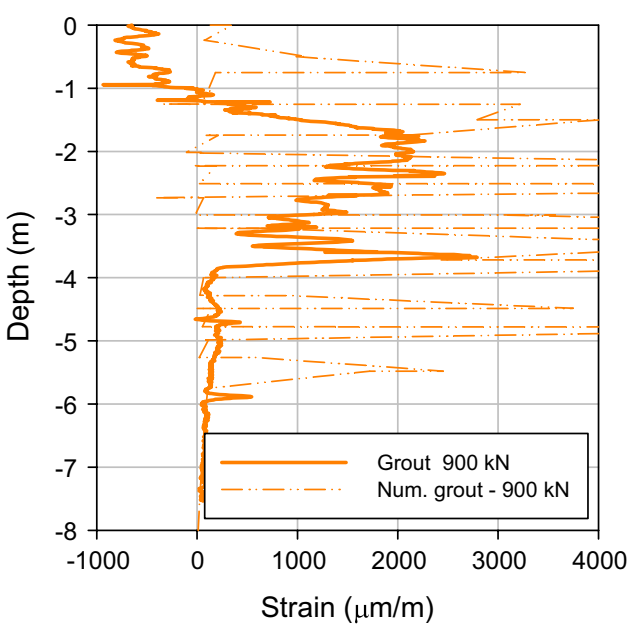

(b) load levels. Again, the comparison can be considered satisfactory. At present, a more detailed analysis of the results (numerical and measurements) is in progress to gain a clear picture of the load transfer between tendon/grout and grout/ soil. Furthermore, two more tests, with similar instrumentation, are underway in different ground conditions in order to identify differences in load transfer mechanisms depending on ground conditions.

\section{Example: slow-moving landslide}

\section{Problem description}

In the course of extension works for a water storage basin, a slow-moving landslide was identified next to the storage basin. The dimensions of the water storage basin are roughly $400 \mathrm{~m}$ in length and $100 \mathrm{~m}$ in width.
The horizontal length of the landslide is roughly $270 \mathrm{~m}$. Movements were detected over a large part of the storage basin length. The inclination of the slope is $30^{\circ}$ on average. Based on inclinometer measurements, the sliding surfaces could be identified between 20 and $40 \mathrm{~m}$ depth below ground surface. The subsurface explorations showed a sliding mass consisting mainly of weathered and sheared rock. Below the sliding mass and below the water storage basin, lacustrine fine sediments, mainly silt, are present. A plan view and a layout of the slow-moving landslide and the water storage basin are shown in Fig. 5. Due to the operation of the pump storage power plant, the water level in the basin changes up to three times a day, whereas the maximum level change is $7.0 \mathrm{~m}$.

Due to the increased risk of a destructive flood wave, a comprehensive monitoring system was installed including inclinometers and pore water pressure gauges. The pore pressure measurements showed changes in pore water 
Fig. 5 Layout and plan view of water storage basin and slowmoving landslide
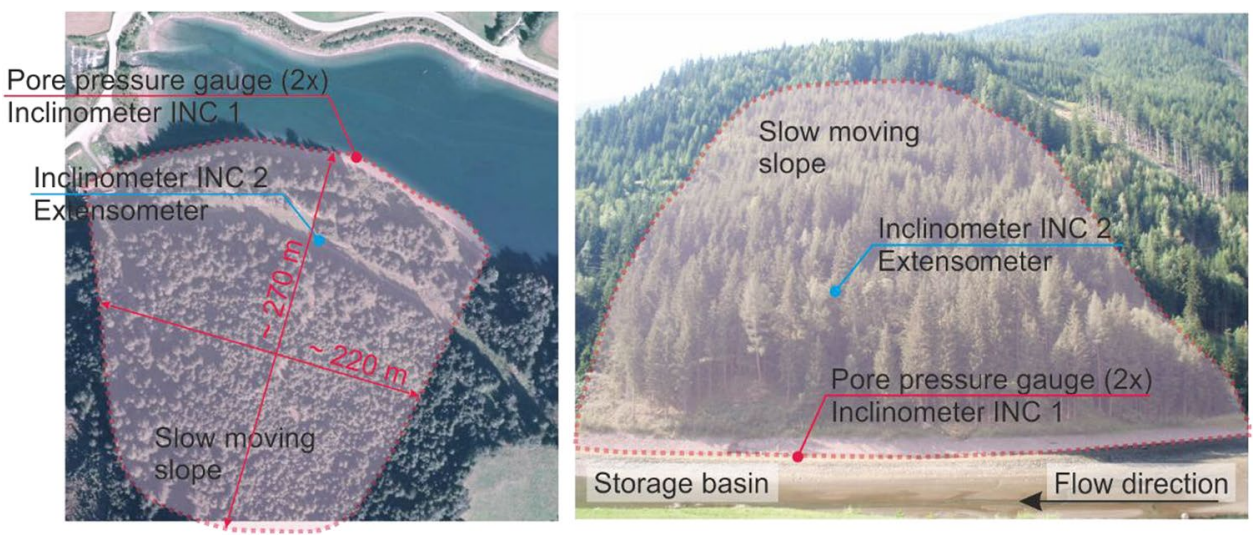

Fig. 6 a Excess pore water pressures due to water level changes; $\mathbf{b}$ correlation between deformation rates and water level changes

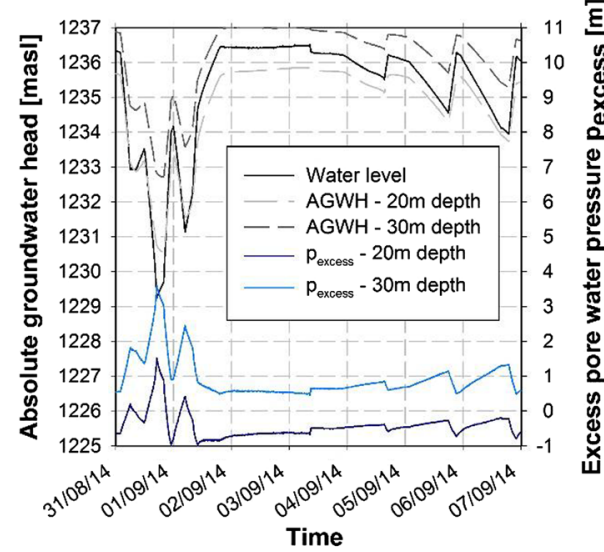

(a)

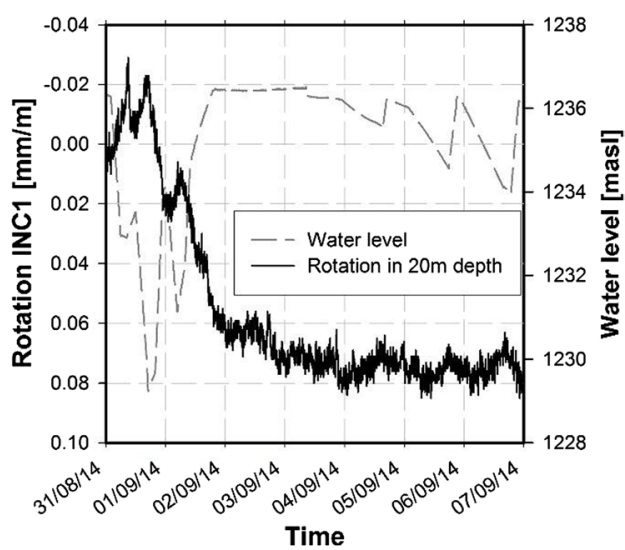

(b) pressures in the subsoil at the toe of the landslide linked to the water table changes in the water storage basin, but it was observed that this was not a one-to-one relationship because positive and negative excess pore pressures have been measured, i.e. the pressure level of the pore pressure measurement is above or below the corresponding water level in the water reservoir. Typical measurement results of the pore pressure gauges are shown in Fig. 6a. For a better understanding of the reasons for these measured excess pore water pressures, a numerical study was carried out. These analyses reveal, as expected, that the magnitude of these excess pore water pressures depends on the ratio between drawdown velocity and soil permeability and furthermore on the ratio between pore water compressibility and soil skeleton compressibility [3]. Also, the presence of air bubbles in the water may contribute to this effect [2]. In Fig. 6a, the excess pore water pressure $p_{-}$excess is defined by the difference of measured and hydrostatic pore water pressure. Deformation measurements using in-place inclinometers revealed a correlation between deformation rates and excess pore water pressures at the slope toe. This shows that the slope deformations are influenced by the water level changes in the water storage basin, as these control the excess pore water pressures in the subsoil. A typical comparison of water level changes and rotation of the inclinometer probe in the major sliding zone is shown in Fig. 6 b.

\section{Numerical model and results}

Preliminary numerical analyses and careful examination of the measurements revealed that water level changes alone could not explain measured displacements. Therefore, a finite element model (Fig. 7), using the code Plaxis 2D [4], was set up incorporating the water level changes from the storage basin but also environmental influences such as rainfall events assuming site-specific precipitation and evaporation. The precipitation was measured on site. The potential evaporation was estimated according to Thornthwaite [10], whereas the influences of the soil suction on the evaporation and the transpiration were neglected due to the lack of measurement data. Furthermore, the lacustrine fine sediments at the slope toe were modelled with the Soft Soil Creep model [11] to model the creep behaviour of these soil layers (see Fig. 7). To achieve appropriate initial conditions concerning the stress state and the hydraulic conditions, the geological history was modelled 
Fig. 7 FE model for numerical back-calculations [1]

Fig. 8 Back-calculated excess pore water pressures [1]

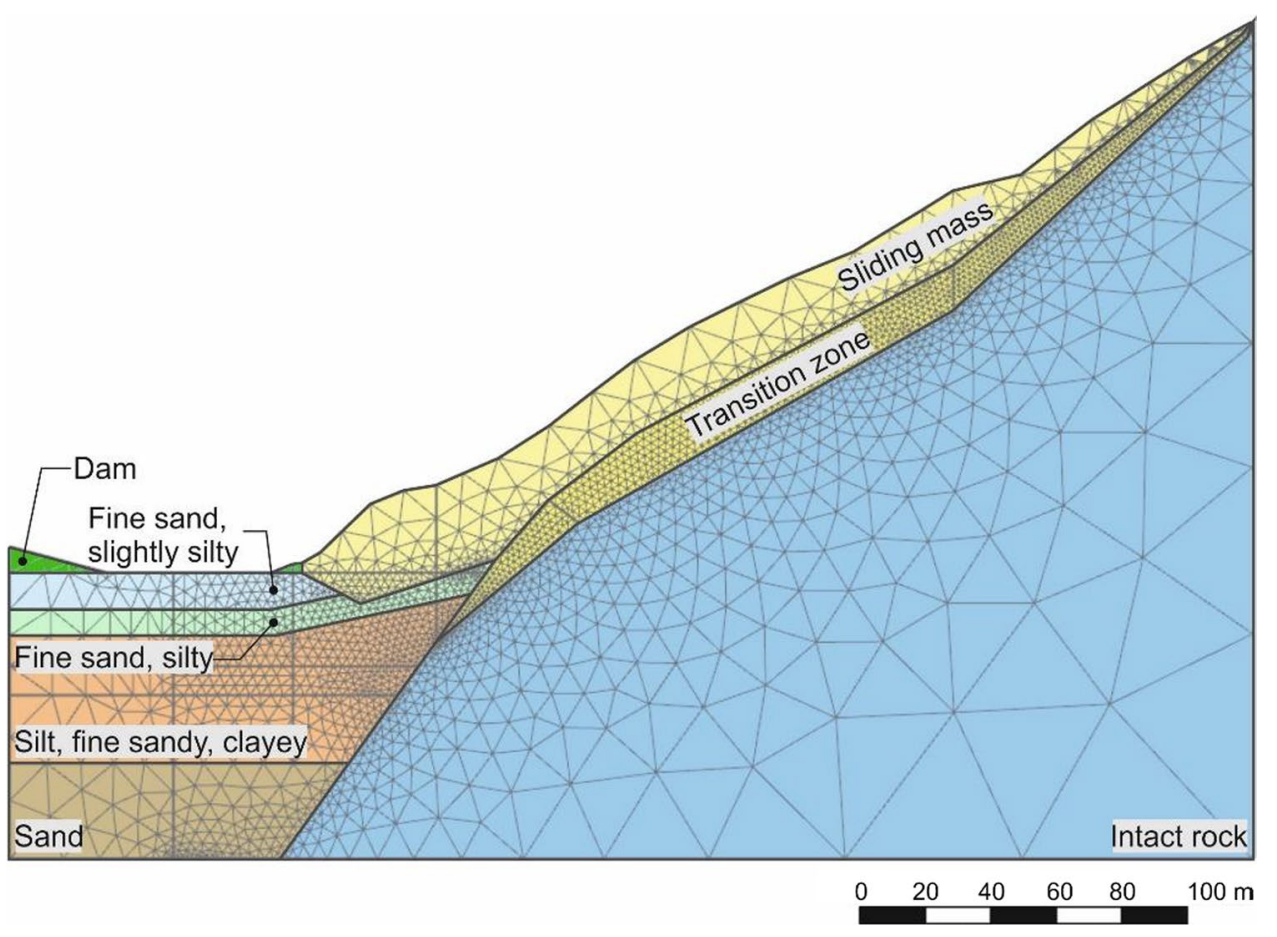

Time

FEA...Finite element analysis

in a simplified way. Afterwards, 1 year with characteristic precipitation and water level changes was simulated [1]. The back-calculation of the pore water pressures was performed for several periods with different types of water level changes. Figure 8 shows a comparison of the measured and calculated excess pore water pressures for the two installed pore water pressure gauges PPG $1(21 \mathrm{~m})$ and PPG 2 (33 m). Furthermore, the water level in the storage 
Fig. 9 Displacements at node E (in the middle of the slope) for different influencing factors [1]

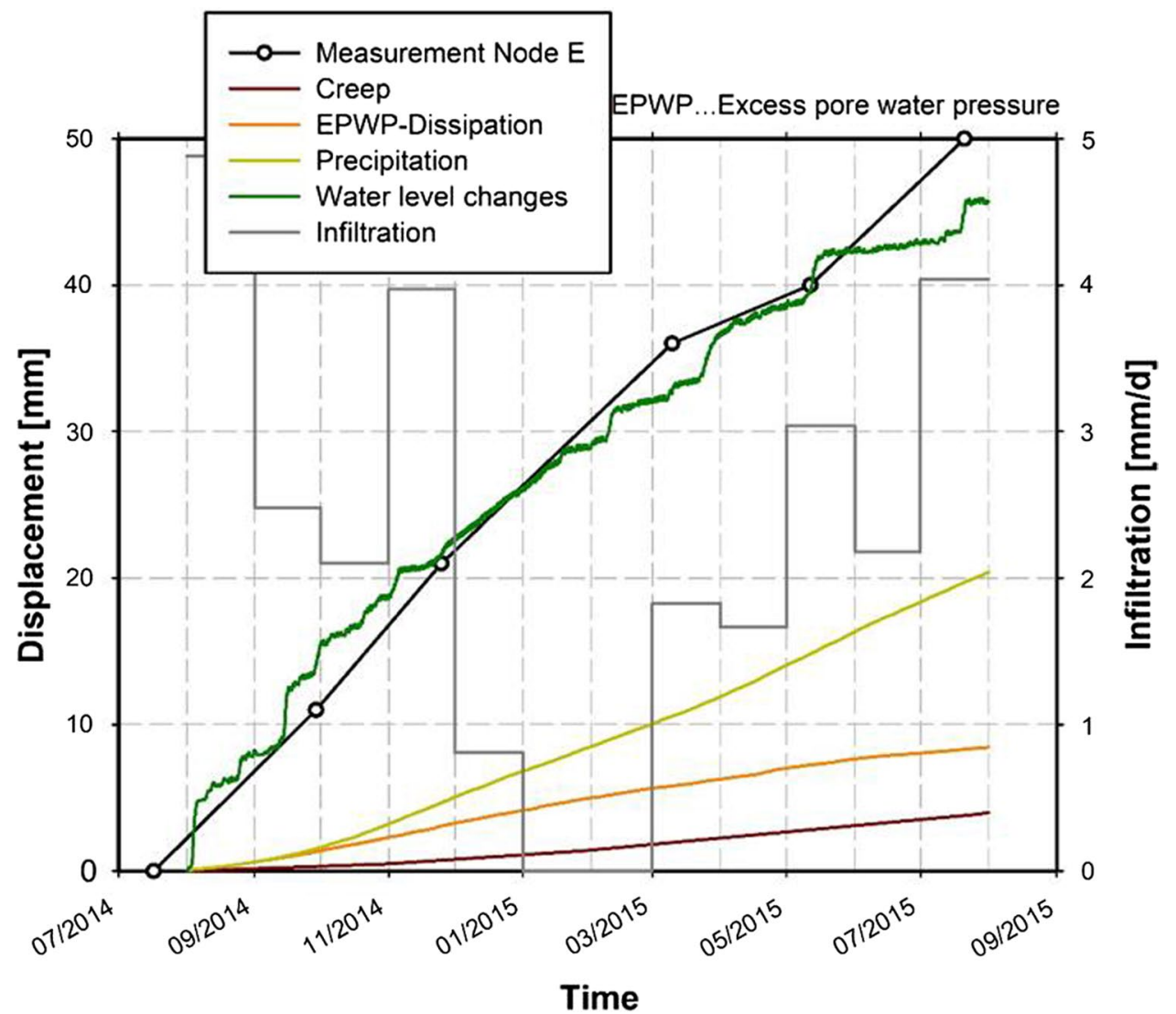

basin is plotted in the diagram. From the comparison in Fig. 8, it can be seen that a good agreement between calculations and measurements could be achieved.

In order to identify the quantitative contribution of the different influencing factors on the total displacements, separate calculation phases were performed. In each phase, a new influencing factor was considered. As an example, the results for a point in the middle of the slope are shown in Fig. 9. The difference between two time-displacement curves is the influence of each additionally considered factor as indicated by the label of the curves. A comparison between the in situ measurements and the total displacements from the calculation indicates a good agreement. According to Fig. 9, the displacements are mainly due to the water level changes in the storage basin but creep behaviour of the lacustrine sediments at the base of the slope and precipitation add to the displacements. The results were evaluated for several points along the slope. It could be clearly shown that the influence of the creep behaviour of the lacustrine fine sediments on the deformations decreases with increasing distance from the slope toe. The influence of precipitation and evaporation is increasing in the middle and upper part of the slope, and the influence of the water level changes on the slope deformations is almost constant over the entire slope. Based on the back-calculations of the slope deformations, it can be argued that the water level changes are the main reason for the slope movements. However, slope movements would also occur without the storage operation but the magnitude of the deformations would be smaller.

\section{Example: numerical simulation of cone penetration test}

\section{Particle finite element method}

In situ investigation methods, such as cone penetration testing (CPT), are frequently used to derive hydraulic and mechanical soil properties from measured tip resistance, 
sleeve friction and pore water pressure via empirical correlations. Experience has shown that CPT provides reasonable results for applications in sand or clay where either drained or undrained behaviour governs the penetration process. However, correlations for partial drainage, as it occurs during penetration in intermediate soils such as silts, are still an ongoing research topic. Recent advances in the numerical simulation of large deformation problems based on a Particle Finite Element Method (PFEM, see [8]) allow to model this kind of penetration problems where a rigid cone penetrates a fully water-saturated soil body. The simulations here are carried out using the platform G-PFEM, short for Geotechnical-PFEM [6, 7], which has been developed within the Kratos framework [5] at the Polytechnic University of Catalonia (UPC) and the Center for Numerical Methods in Engineering (CIMNE). In G-PFEM, the quasi-static linear momentum and mass balance equations are formulated for a solid and fluid phase adopting an updated Lagrangian description. The basic idea behind the PFEM is a continuous remeshing of critical regions of the domain, where new nodes can be
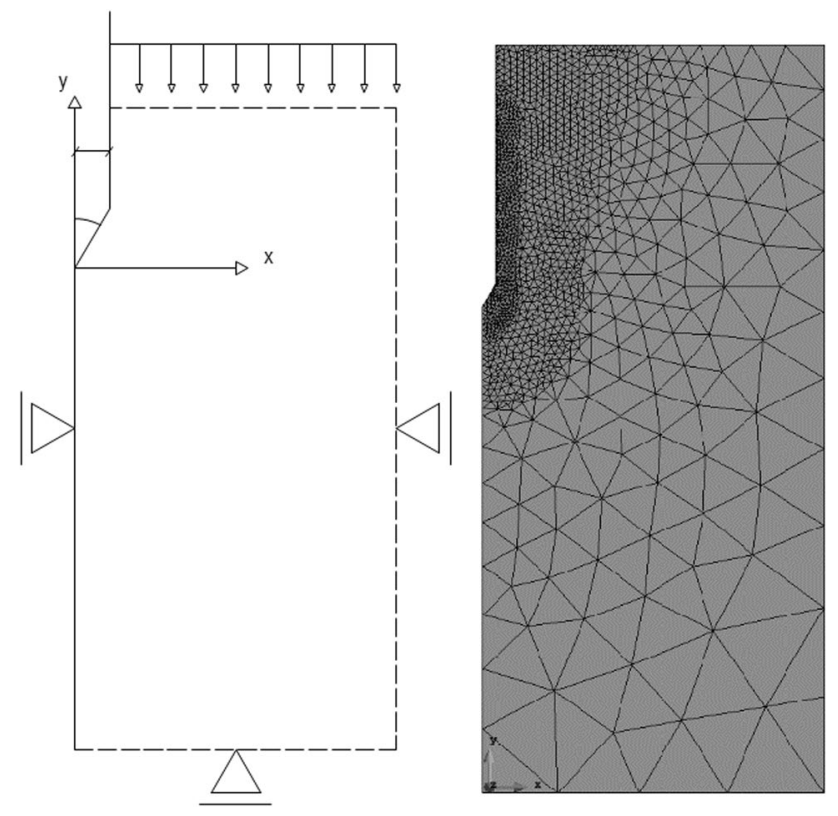

Fig. 10 Axisymmetric model (left) and refined mesh during penetration process (right) added and old ones removed, in order to deal with large deformations and avoid excessive mesh distortion. This strategy results in an increased computational cost and therefore low-order elements in combination with a mixed formulation of the problem are used. In order to avoid locking effects, an additional degree of freedom, namely the determinant $\mathbf{J}$ of the deformation gradient, is introduced on top of the displacement and water pressure fields $u$ and pw [7]. Furthermore, the problem is stabilised using the Polynomial Pressure Projection. The interested reader is referred to Monforte et al. [6] and Monforte et al. [7] for a more detailed outline of the PFEM.

\section{Numerical model for cone penetration}

Modelling a CPT involves an ideally rigid cone that penetrates a deformable two-phase medium at a constant velocity. This leads to an axisymmetric model consisting of a rectangular box with a height of $1.1 \mathrm{~m}$ and a width of $0.5 \mathrm{~m}$. The cone radius $\mathrm{R}$ measures $1.78 \mathrm{~cm}$ with a tip angle of $60^{\circ}$ corresponding to the standard geometry (base area of $10 \mathrm{~cm}^{2}$ ). The penetration starts from an initial position where the cone is located at a depth of $10 \mathrm{~cm}$. The lateral and lower boundaries are fixed in normal direction while an overburden pressure can be applied at the top of the domain. Moreover, free drainage is allowed at the boundaries except along the symmetry axis. Figure 10 shows the basic model. From a mathematical point of view, the contact between cone and soil body is described by a set of constraints and a penalty method is adopted. The contact algorithm is explained in detail in Monforte et al. [6]. The constitutive behaviour of the soil is described by means of the Modified Cam Clay (MCC) model, and the parameters for this particular analysis are given in Table 3 .

\section{Influence of anisotropic permeability}

In order to study the effect of anisotropic permeability, the set-up described in the previous section was analysed with a standard penetration velocity of $2 \mathrm{~cm} / \mathrm{s}$, a smooth interface between cone and soil and anisotropic permeability, whereas two cases have been investigated. Test

Table 3 Input parameters for MCC model

\begin{tabular}{llllllll}
\hline$\rho_{\mathrm{s}}\left(\mathrm{kg} / \mathrm{m}^{3}\right)$ & $\rho_{\mathrm{w}}\left(\mathrm{kg} / \mathrm{m}^{3}\right)$ & $\lambda^{*}(-)$ & $\kappa^{*}(-)$ & $\varphi^{\prime}\left({ }^{\circ}\right)$ & $M(-)$ & $G_{0}(\mathrm{kPa})$ & $\alpha(-)$ \\
\hline 1700 & 1000 & 0.015 & 0.005 & 22.5 & 0.88 & 2900 & 0 \\
\hline OCR $(\mathrm{kPa})$ & $p_{\mathrm{c} 0}(\mathrm{kPa})$ & $K_{\mathrm{w}}(\mathrm{m} / \mathrm{s})$ & $k_{\mathrm{v}}(\mathrm{m} / \mathrm{s})$ & $k_{\mathrm{h}}(-)$ & $K_{0}\left({ }^{\circ}\right)$ & $\varphi_{\text {int }}(-)$ & $e_{0}(-)$ \\
\hline 1 & 100 & $1 \times 10^{8}$ & $2 \times 10^{-8}$ & $2 \times 10^{-7}$ & 0.7 & 7 & 0.5 \\
\hline
\end{tabular}




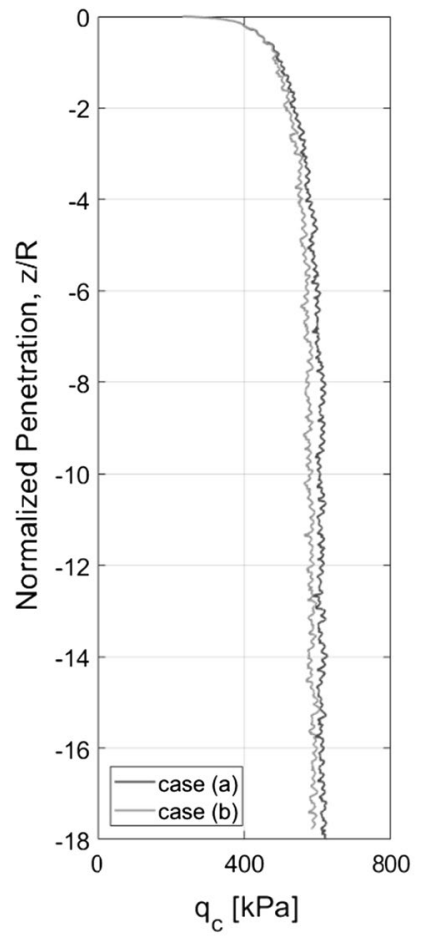

(a)

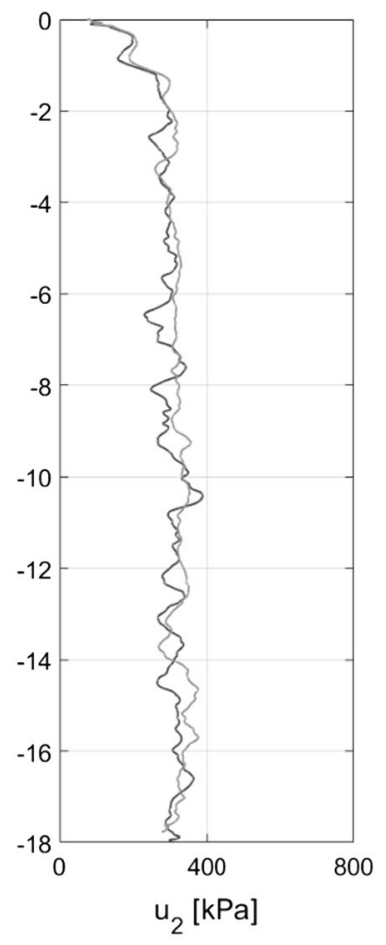

(b)
Fig. 11 Comparison of $q_{\mathrm{c}}$ and $u_{2}$ for inverted anisotropic permeabilities; case (a) with $k_{\mathrm{v}}=2 \times 10^{-8} \mathrm{~m} / \mathrm{s}, k_{\mathrm{h}}=2 \times 10^{-7} \mathrm{~m} / \mathrm{s}$ and case (b) with $k_{\mathrm{v}}=2 \times 10^{-7} \mathrm{~m} / \mathrm{s}, k_{\mathrm{h}}=2 \times 10^{-8} \mathrm{~m} / \mathrm{s}$

case (a) considers an increased horizontal permeability with $k_{\mathrm{h}}=2 \times 10^{-7} \mathrm{~m} / \mathrm{s}$ and $k_{\mathrm{v}}=2 \times 10^{-8} \mathrm{~m} / \mathrm{s}$, while case (b) simulates the opposite case $\left(k_{\mathrm{h}}=2 \times 10^{-8} \mathrm{~m} / \mathrm{s}\right.$ and $\left.k_{\mathrm{v}}=2 \times 10^{-7} \mathrm{~m} / \mathrm{s}\right)$. The anisotropy is crucial for the hydraulic behaviour and prescribes the preferred flow direction which is horizontal for case (a) and vertical for case (b). The profiles of $q_{\mathrm{c}}$ and $u_{2}$ are compared in Fig. 11 and in both cases (a) and (b) overall undrained behaviour with $u_{2}$ ( $u_{2}=$ most common position in CPT for measuring pore pressures) being around $320 \mathrm{kPa}$ and $q_{\mathrm{c}}$ of $600 \mathrm{kPa}$ is observed. However, a closer look reveals that test case (a) gives a slightly lower pore pressures (315 $\mathrm{kPa}$ vs $330 \mathrm{kPa}$ ) and a higher tip resistance (610 $\mathrm{kPa}$ vs $585 \mathrm{kPa}$ ) compared to case (b). These observations are consistent with the assumption of a preferred flow direction due to anisotropy. As the cone penetrates the soil, radial (or rather horizontal) flow is dominantly caused by the geometric boundary conditions of the test. Thus, for case (a), the preferred flow directions due to anisotropy and problem geometry coincide which leads to increased drainage of the system. For case (b), the opposite occurs and the main flow direction is vertical. Consequently, although the overall behaviour is rather undrained, differences can be observed locally which may become important when deriving coefficients of consolidation from dissipation tests.

The effect of anisotropic permeability on the pore pressure field is shown in Fig. 12. It is observed that the order of magnitude of the calculated water pressures is the same, again as expected for undrained conditions, but the distribution differs. For case (b), the pressure bulb has an increased vertical extension along the preferred drainage direction. Further studies are currently undertaken to assess in more detail the effect of partial drainage in intermediate soils on tip resistance, sleeve friction and pore water pressures.

\section{Conclusion}

The numerical simulation of an anchor pull-out test showed that the predicted load-displacement curve ("class-A" prediction) and the one obtained in situ showed very good agreement. The ultimate pull-out load is achieved when the shear strength is mobilised along the entire interface grout-soil. The numerical simulation indicated that the strains in the tendon are highly influenced by the development of cracks in the grout of the fixed length which could be captured by applying an advanced constitutive model for the grout.

The second example, namely the back-analysis of a slowmoving landslide at a water reservoir, proved that complex mechanisms contributing to slope movement, such as water level fluctuations in the reservoir, creep phenomena in soft lacustrine deposits present at the toe of the slope and environmental effects such as rainfall infiltration can be accounted for in numerical analyses. It is acknowledged, however, that due to significant uncertainties in input parameters the solutions presented are by no means rigorous and unique but still provide a better insight into the mechanical behaviour of such slopes and will help the experienced geotechnical engineer in defining appropriate mitigating measures.

In the last example, it is shown that G-PFEM is an appropriate tool for simulating CPT. The application presented looked into the effect of considering anisotropic permeability of the soil layer. It could be shown that anisotropy influences the local pore pressure field under globally undrained conditions which may have a consequence when deriving coefficients of consolidation from dissipation tests. 
Fig. 12 Pore pressure fields for inverted anisotropic permeabilities; case (a) with $k_{\mathrm{v}}=2 \times 10^{-8} \mathrm{~m} / \mathrm{s}$, $k_{\mathrm{h}}=2 \times 10^{-7} \mathrm{~m} / \mathrm{s}$ and case (b) with $k_{\mathrm{v}}=2 \times 10^{-7} \mathrm{~m} / \mathrm{s}$, $k_{\mathrm{h}}=2 \times 10^{-8} \mathrm{~m} / \mathrm{s}$

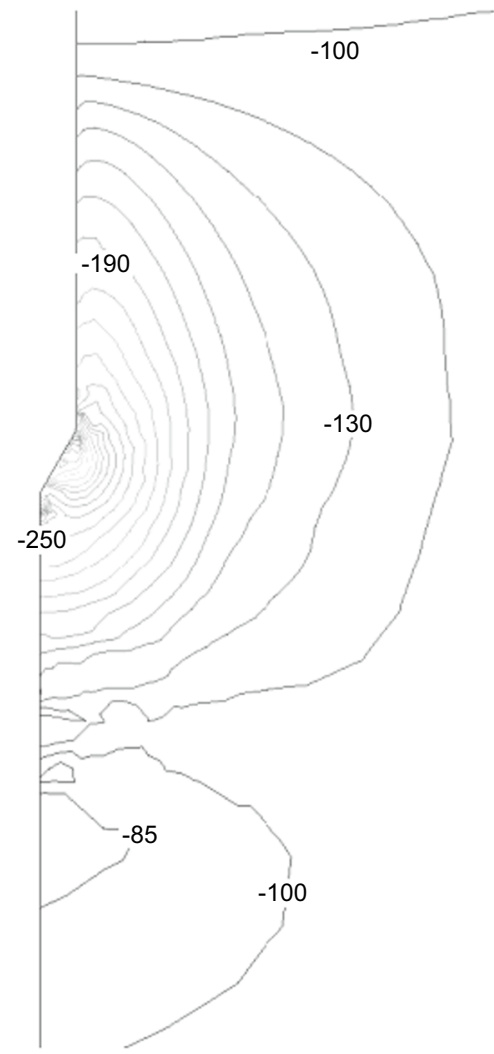

(a)

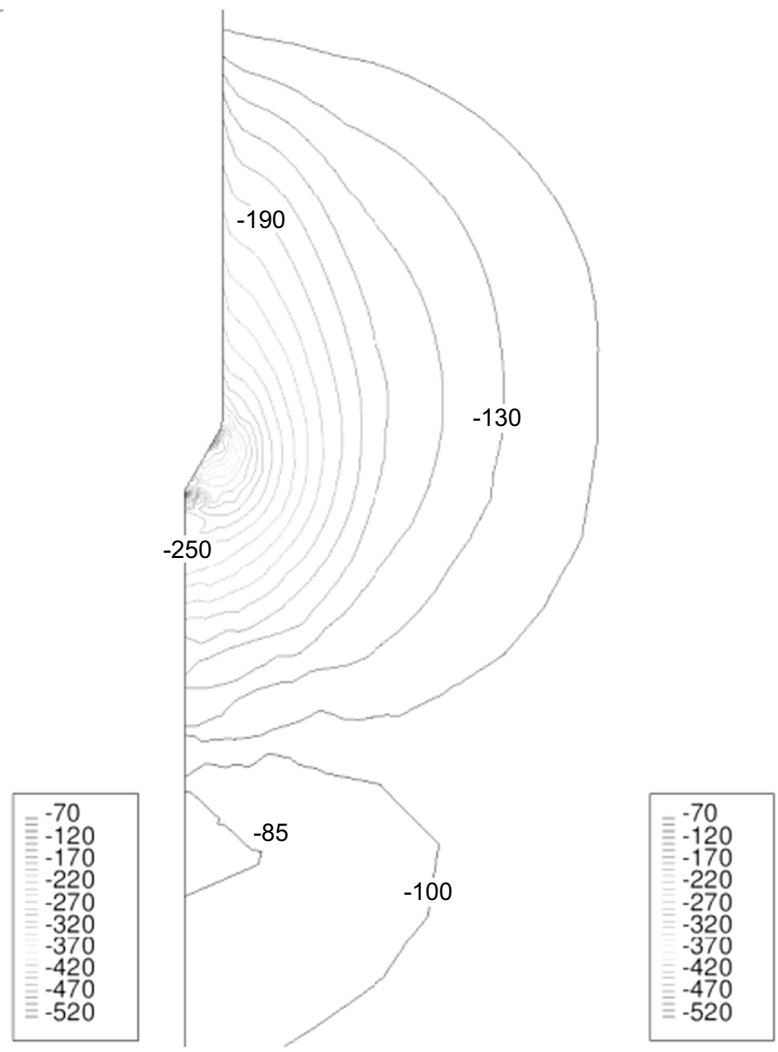

(b)
Acknowledgements Open access funding provided by Graz University of Technology.

Open Access This article is distributed under the terms of the Creative Commons Attribution 4.0 International License (http://creativeco mmons.org/licenses/by/4.0/), which permits unrestricted use, distribution, and reproduction in any medium, provided you give appropriate credit to the original author(s) and the source, provide a link to the Creative Commons license, and indicate if changes were made.

\section{References}

1. Ausweger GM (2017) Influences of water level changes on the behaviour of a slow moving landslide-in situ measurements, model test and numerical analyses. $\mathrm{PhD}$ thesis, Graz University of Technology

2. Ausweger GM, Schweiger HF (2016) Numerical study on the influence of entrapped air bubbles on the time-dependent pore pressure distribution in soils due to external changes in water level. In: Proceedings of the 3rd European conference on unsaturated soils, paper \#16010, Paris, 12-14 Sept 2016

3. Ausweger GM, Schweiger HF (2017) Numerical investigation of excess pore water pressures due to external fluctuating water tables. In: Proceedings 15 th international conference computer methods and recent advances in geomechanics, Wuhan, China
4. Brinkgreve RBJ, Kumarswamy S, Swolfs WM (2016) PLAXIS 2016. Finite element code for soil and rock analyses, user manual. Plaxis bv, Delft

5. Dadvand P, Rossi R, Oñate E (2010) An object-oriented environment for developing finite element codes for multidisciplinary applications. Arch Comput Methods Eng 17(3):253-297

6. Monforte L, Arroyo M, Carbonell JM, Gens A (2017) Numerical simulation of undrained insertion problems in geotechnical engineering with the particle finite element method (PFEM). Comput Geotech 82:144-156

7. Monforte L, Carbonell JM, Arroyo M, Gens A (2017) Performance of mixed formulations for the particle finite element method in soil mechanics problems. Comput Part Mech 4(3):269-284

8. Oñate E, Idelsohn SR, Celigueta MA, Rossi R, Marti J, Carbonell JM, Ryzakov P, Suárez B (2011) Advances in the particle finite element method (PFEM) for solving coupled problems in engineering. Part Based Methods 25:1-49

9. Schädlich B, Schweiger HF (2014) A new constitutive model for shotcrete. In: Hicks MA, Brinkgreve RBJ, Rohe A (eds) Proceedings of the numerical methods in geotechnical engineering. Taylor \& Francis Group, London, pp 103-108

10. Thornthwaite CW (1948) An approach toward a rational classification of climate. Geogr Rev 38(1):55-94

11. Vermeer PA, Neher HP (1999) A soft soil model that accounts for creep. In: Proceedings of the international symposium beyond 2000 in computational geotechnics 